\title{
Survival in Primary Carcinoma of the External and Middle Ear Is Strongly Dependent on Stage at Diagnosis
}

\author{
Toru Ugumori $^{1}$, Jun Hyodo ${ }^{2}$, Naohito Hato ${ }^{1}$, Kiyofumi Gyo ${ }^{1}$ \\ ${ }^{1}$ Departmentof Otolaryngology, Ehime University, Toon, Japan \\ ${ }^{2}$ Department of Otolaryngology, Takanoko Hospital, Matsuyama, Japan \\ Email: ugumorit@m.ehime-u.ac.jp
}

Received July 8, 2013; revised August 5, 2013; accepted September 2, 2013

Copyright (C) 2013 Toru Ugumori et al. This is an open access article distributed under the Creative Commons Attribution License, which permits unrestricted use, distribution, and reproduction in any medium, provided the original work is properly cited.

\begin{abstract}
Conclusion: Early-stage detection of temporal bone carcinoma improves the survival rate. When detected at an advanced stage, predicted prognosis is poor even with a combination of surgery, radiotherapy and chemotherapy. Objectives: We evaluated treatment strategies and survival rates in cases of carcinomas of the external and middle ear. Method: Retrospective review of patients treated at Ehime University Hospital during the 32 years from 1977 to 2008. Subjects were 41 patients, consisting of 21 men and 20 women with a mean age of 63.2 years. Modified Pittsburgh staging system: stage I in 11 cases (27\%), stage II in 4 (10\%), stage III in 6 (15\%) and stage IV in 20 (49\%). Histopathology: squamous cell carcinoma (SCC) in 35 cases, adenoid cystic carcinoma (ACC) in 3, and adenocarcinoma (AC) in 3. Thirty-eight patients were treated by surgery. Radiation was added postoperatively in 23 patients. Three patients were treated by chemoradiotherapy. Results: The survival rate of carcinomas detected at an advanced stage was poor with a disease-specific 5-year survival rate of $100 \%$ in early-stage disease (stage I and II) versus $20.8 \%$ in stage III and $27.5 \%$ in stage IV disease, irrespective of histopathology of the tumor.
\end{abstract}

Keywords: Survival; Staging; External Auditory Canal; Middle Ear

\section{Introduction}

Primary carcinoma of the external and middle ear is a rare disease entity which affects 0.8 - 6 per million of population per year [1]. It occurs most frequently in people aged 50 - 70 years, with equal gender distribution [2]. The initial presenting symptoms are non-specific, and diagnosis therefore tends to be delayed. When detected at an advanced stage, predicted prognosis is poor, even with a combination of surgery, radiotherapy and chemotherapy. By histological subtype, squamous cell carcinoma (SCC) accounts for approximately $90 \%$ of all primary malignant tumors of the temporal bone [3]. Complete surgical resection with a clear margin is a generally accepted therapeutic modality, but this is often difficult as temporal bone carcinomas are often found in the advanced stage. Adjunct radiotherapy and chemotherapy are recommended in cases with incomplete resection, although large-scale clinical evidence concerning their effects is lacking, mainly because of the rarity of the disease. At present, no universal consensus on optimal treatment of temporal bone carcinoma has yet to be es- tablished.

Here, we reviewed 41 patients with primary temporal bone carcinomas treated in our hospital over the past 32 years. The aim of this paper was to evaluate treatment strategies and survival rates of our patients, particularly in relation to tumor stage.

\section{Material and Methods}

The study was conducted by retrospective review of medical records. Subjects were 41 consecutive patients with primary temporal bone carcinoma who were treated in our hospital between 1977 and 2008. The Patients and lesion characteristics are listed in Table 1. Tumor grade was classified using the modified Pittsburgh staging system [4] (Table 2). According to the system, in total, there were 11 T1, 4 T2, 6 T3, and 20 T4 in our study (Table 3), which were corresponding to 11 stage I (T1N0M0), 4 stage II (T2NOM0), 6 stage III (T3NOM0), and 20 stage IV (T4N0M0/T4N1M0) tumors. So we state the T classification as a stage here. Cervical lymph node metastasis was found only in one patient, while involvement of the 
dura mater was seen in 14 patients, mandibular joint in 10 , parotid gland in 8 , sigmoid sinus in 4, cochlea in 2, facial nerve in 2, and carotid artery in 1, when involved sites were counted separately. These cases were all classified as stage IV. No distant metastases were seen preoperatively, although three patients subsequently died of lung metastasis. Three types of surgical procedure were employed [4]: 1) Local resection (LR; so-called sleeve resection), 2) Lateral temporal bone resection (LTBR; some radical mastoidectomy), 3) Subtotal temporal bone resection (STBR). The standard surgical protocol and number of patients was displayed in Table 4. After removal of the tumor, the orifice of the ear canal was kept open to allow the observation of possible local recurrence in postoperative follow-up. For patients with tumors extending to the parotid gland or causing metastasis to neck lymph nodes, parotidectomy and/or neck dissection was done in addition to subtotal TBR. As the incidence of temporal bone ACC and AC is low and no treatment strategy has yet been established, treatment was done by the same protocol as that for SCC [5]. Details of ACC and AC cases are summarized in Table 5. Twentyfour patients with stage III or IV disease in whom tumor resection was considered incomplete under went subsequent adjuvant radiotherapy. Radiation was started 2 to 4 weeks after surgery, with total radiation dose set to 66
Gy. We did not use anticancer agents until 1983, after which chemoradiotherapy was started in consenting patients using one of three anticancer agents, namely cisplatin in combination with adjuvant radiotherapy in one patient with stage IV disease; TS- $1^{\circledR}$ (tegafur-gimeraciloteracil potassium) in seven patients; and $5 \mathrm{FU}^{\circledR}$ (fluorouracil) in two patients. The three SCC patients who did not

Table 1. Patients and lesion characteristics.

\begin{tabular}{cc} 
No. of patients & 41 \\
Age (range), y & $63.2(31-87)$ \\
Sex, men/women & $21 / 20$ \\
Primary site & \\
Right & 23 \\
Left & 18 \\
External auditory canal & 29 \\
Middle ear & 11 \\
Unknown & 1 \\
Histopathology & \\
Sqamous cell carcinoma & 35 \\
Adenoid cystic carcinoma & 3 \\
Adenocarcinoma & 3 \\
\hline
\end{tabular}

Table 2. Moody's modified Pittsburgh staging system.

\begin{tabular}{|c|c|}
\hline Factor & Description/distinguishing features/characteristics \\
\hline \multicolumn{2}{|c|}{ T classification } \\
\hline $\mathrm{T} 1$ & Limited to the external auditory canal without bony erosion or evidence of soft tissue involvement \\
\hline $\mathrm{T} 2$ & Limited to the external auditory canal with bone erosion (not full-thickness) or limited soft tissue involvement ( $<5$ mm) \\
\hline Т3 & $\begin{array}{l}\text { Erosion through the osseous external auditory canal (full thickness) with limited soft tissue involvement ( }<5 \mathrm{~mm}) \text {, or } \\
\text { tumor involving the middle ear and/or mastoid }\end{array}$ \\
\hline $\mathrm{T} 4$ & $\begin{array}{l}\text { Erosion of the cochlea, petrous apex, medial wall of the middle ear, carotid canal, jugular foramen, or dura; or tumor } \\
\text { with extensive soft tissue involvement ( }>5 \mathrm{~mm} \text {, such as involvement of the temporomandibular joint or styloid process); } \\
\text { or evidence of facial paresis }\end{array}$ \\
\hline \multicolumn{2}{|c|}{ N classification } \\
\hline N0 & No regional nodes identified \\
\hline N1 & Single metastatic regional node $<3 \mathrm{~cm}$ in size \\
\hline $\mathrm{N} 2 \mathrm{~b}$ & Multiple ipsilateral metastatic lymph nodes \\
\hline N2c & Contralateral metastatic lymph node \\
\hline N3 & Metastatic lymph node $>6 \mathrm{~cm}$ in size \\
\hline \multicolumn{2}{|c|}{ Overall stage } \\
\hline I & T1 N0 \\
\hline II & T2 N0 \\
\hline III & T3 N0 \\
\hline IV & T4 N0 \\
\hline IV & $\mathrm{T} 1-\mathrm{T} 4 \mathrm{~N}+$ \\
\hline
\end{tabular}


Table 3. TNM staging.

\begin{tabular}{|c|c|c|}
\hline TNM staging & No. of patients & Percentage \\
\hline \multicolumn{3}{|l|}{ Size of tumor $(\mathrm{T})$} \\
\hline $\mathrm{T} 1$ & 11 & $27 \%$ \\
\hline $\mathrm{T} 2$ & 4 & $10 \%$ \\
\hline T3 & 6 & $15 \%$ \\
\hline $\mathrm{T} 4$ & 20 & $49 \%$ \\
\hline \multicolumn{3}{|c|}{ Lymph node metastasis (N) } \\
\hline N0 & 40 & $98 \%$ \\
\hline N1 & 1 & $2 \%$ \\
\hline \multicolumn{3}{|c|}{ Distant metastasis (M) } \\
\hline M0 & 41 & $100 \%$ \\
\hline M & $\mathbf{0}$ & 0\% \\
\hline \multicolumn{3}{|l|}{ Clinical stage } \\
\hline I & 11 & $27 \%$ \\
\hline II & 4 & $10 \%$ \\
\hline III & 6 & $15 \%$ \\
\hline IV & 20 & $49 \%$ \\
\hline
\end{tabular}

Table 4. Types of surgery.

\begin{tabular}{cc}
\hline Surgery & Specimen resected \\
\hline LR & Skin of external auditory canal \\
LTBR & En bloc removal of externalauditory canal, tympanicmembrane, malleus, and incus optional: parotid, \\
mandibularcondyle, infratemporal fossa, or neck dissection & 6 \\
STBR & LTBR plus otic capsule optional: facial nerve, superior and posterior dura, or sigmoid sinus \\
\hline
\end{tabular}

LR indicates local resection; LTBR, lateral temporal bone resection; STBR, subtotal temporal bone resection.

Table 5. Patient data for cases of adenoidcystic carcinoma (ACC) and adenocarcinoma (AC).

\begin{tabular}{|c|c|c|c|c|c|c|c|c|c|}
\hline No. & $\begin{array}{l}\text { Age }(\mathrm{yr}) \text {, } \\
\text { gender }\end{array}$ & Histology & $\mathrm{T}$ & $\begin{array}{c}\text { Lymph } \\
\text { node/metastasis }\end{array}$ & $\begin{array}{c}\text { Tumor } \\
\text { extension/invasion }\end{array}$ & $\begin{array}{l}\text { Surgical } \\
\text { procedure }\end{array}$ & $\begin{array}{c}\text { Radiation/ } \\
\text { Chemotherapy }\end{array}$ & Outcome & $\begin{array}{l}\text { Follow-up } \\
\text { period }\end{array}$ \\
\hline 1 & $40, \mathrm{~F}$ & $\mathrm{AC}$ & 1 & $-/-$ & - & Sleeve resection & - & $\mathrm{CR}$ & $55 \mathrm{mo}$ \\
\hline 2 & $66, \mathrm{M}$ & AC & 4 & $-/-$ & Middle ear, ICA & Partial TBR & - & dead (8 mo) & \\
\hline 3 & $81, \mathrm{~F}$ & $\mathrm{AC}$ & 4 & $-/-$ & Dura mater, mandibular joint & Partial TBR & - & dead (19 mo) & \\
\hline 4 & $75, \mathrm{~F}$ & $\mathrm{ACC}$ & 2 & $-/-$ & Canal bone erosion & Lateral TBR & - & CR & $55 \mathrm{mo}$ \\
\hline 5 & $31, \mathrm{~F}$ & ACC & 2 & $-/-$ & Canal bone erosion & Lateral TBR & - & CR & $88 \mathrm{mo}$ \\
\hline 6 & $48, \mathrm{~F}$ & ACC & 4 & $-/-$ & Middle ear, mandibular joint & Partial TBR & - & dead (33 mo) & \\
\hline
\end{tabular}

ICA: internal carotid artery; TBR: temporal bone resection; CR: complete remission.

undergo surgery were treated with 66 Gy of radiation plus TS-1 chemotherapy. Postoperative follow-up primarily consisted of careful otoscopic observation. Scar tissue after surgery or radiation often became indurated and was difficult to distinguish from recurrence, necessitating repeated biopsy and/or CT examination when any recurrence was suspected. Median follow-up period for the 22 survivors was 59 months (range, 19 - 115 months). Disease-specific survival rates were calculated by the Kaplan-Meier method and the results were analyzed by the log-rank test. In this study, $p$ values less than 0.05 were regarded as statistically significant.

\section{Results}

Presenting symptoms of temporal bone carcinoma varied, with otorrhea in 28 patients, otalgia in 24, hearing loss in 19 , facial palsy in 9 , ear itching in 8 , tinnitus in 7 , feeling of ear fullness in 6, bleeding in 3, and ear tumor in 2 . Importantly, 25 of 41 patients had a history of chronic 
otitis media or recurrent external otitis, suggesting that continuous external or middle ear inflammation might be a predisposing factor to temporal bone carcinoma. Postoperative recurrence occurred in $55.3 \%$ (21/38) of patients, all of whom had stage III or IV disease. Survival rates were closely related to carcinoma stage. In early (stage I and II) disease, disease-specific 5-year survival rate was $100 \%$, versus $20.8 \%$ in stage III and $27.5 \%$ in stage IV disease (Figure 1). On univariate analysis, Clinical stage $(p<0.0001)$ and Tumor site $(p=0.036)$ were found to be significant prognostic factors (Table 6). Final outcomes did not significantly differ by differences in tumor histopathology, with overall 5-year survival rates of $54.8 \%$ in SCC $(n=35), 66.7 \%$ in ACC $(n=3)$, and $33.3 \%$ in AC $(n=3)$. Rather, survival rate depended on tumor stage. Of the three patients who did not undergo surgery, two subsequently died of carcinoma, while one is still alive and in a tumor-free condition. In summary, 22 of 39 patients were still alive at 5 years after diagnosis, of whom 18 were tumor-free and 4 had static disease, while 17 died of temporal bone carcinoma. The remaining two patients died of conditions not related to carcinoma, namely cerebral hemorrhage and heart failure in one each.

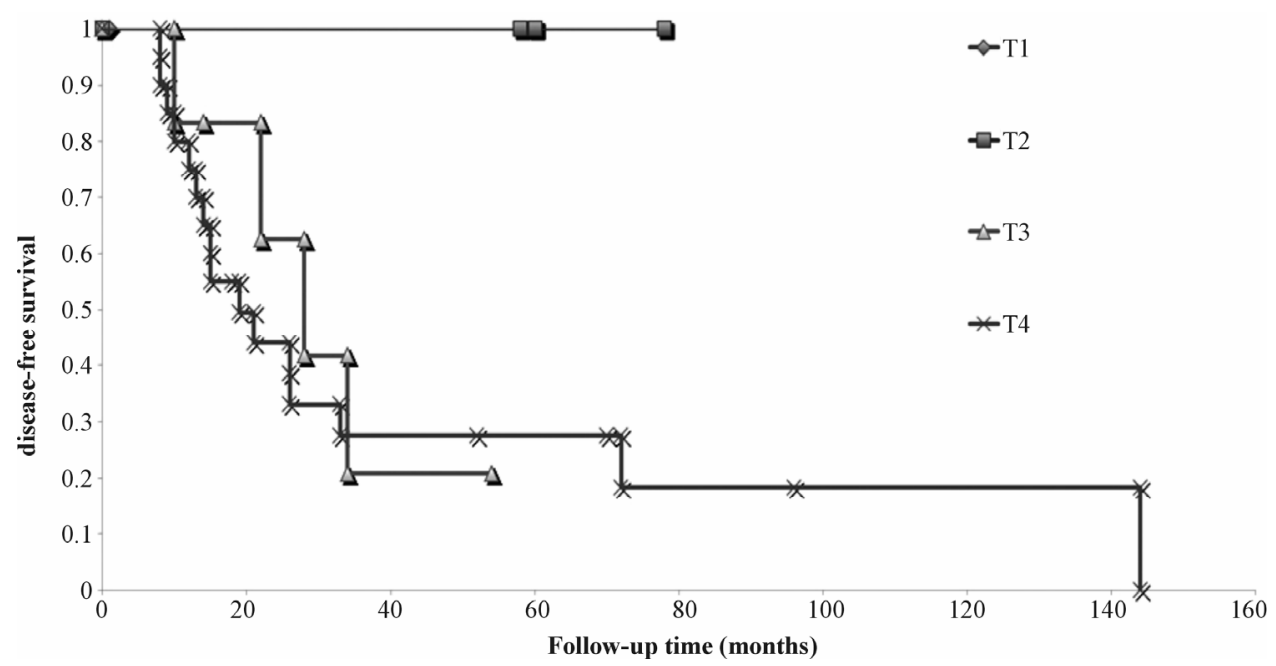

Figure 1. Kaplan-Meier survival curves for patients with external and middle ear carcinoma.

Table 6. Univariate analysis of various potential prognostic factors for disease-specific survival.

\begin{tabular}{|c|c|c|c|}
\hline \multirow{2}{*}{ Variable } & \multirow{2}{*}{ No. of patients } & \multicolumn{2}{|c|}{ Univariate analysis } \\
\hline & & 5-y DSS rate (\%) & $p$ \\
\hline \multicolumn{4}{|l|}{ Clinical stage } \\
\hline Stage I and II & 15 & $100 \%$ & \multirow{2}{*}{$<0.0001$} \\
\hline Stage III and IV & 26 & $26 \%$ & \\
\hline \multicolumn{4}{|l|}{ Treatment modality } \\
\hline Surgery & 15 & $73 \%$ & 0.26 \\
\hline Surgery + RT & 14 & $48 \%$ & \multirow{2}{*}{0.097} \\
\hline Surgery + RT + Chemo & 8 & $13 \%$ & \\
\hline \multicolumn{4}{|l|}{ Tumor site } \\
\hline External auditory canal & 29 & $64 \%$ & \multirow{2}{*}{0.036} \\
\hline Middle ear & 11 & $33 \%$ & \\
\hline \multicolumn{4}{|l|}{ Gender } \\
\hline Female & 20 & $53 \%$ & \multirow{2}{*}{0.98} \\
\hline Male & 21 & $54 \%$ & \\
\hline \multicolumn{4}{|l|}{ Age (y) } \\
\hline$<65$ & 20 & $50 \%$ & \multirow{2}{*}{0.62} \\
\hline$>65$ & 21 & $59 \%$ & \\
\hline
\end{tabular}

DSS = Disease-specific survival; RT = Radiotherapy; Chemo = Chemotherapy. 


\section{Discussion}

Prognosis of temporal bone carcinoma is generally good when detected at an early stage. However, early detection is often difficult, mainly due to the absence of pathognomonic signs or symptoms related to this disease. A slowly worsening or treatment-resistant lesion in the ear canal might be one key to suspect carcinoma. Kuhel et al. [2] analyzed the clinical data of 442 patients described in the literature and reported that otorrhea (61\%), otalgia (51\%), and a mass in the external ear canal (37\%) were the most common symptoms of temporal bone carcinoma. Yin et al. [6] analyzed the complaints of 95 patients with temporal bone SCC and reported that the main symptoms were otorrhea in $42.1 \%$, otalgia in $24.2 \%$, bloody otorrhea in $15.8 \%$, and tumor in the ear canal in $11.6 \%$. In most of Yin's patients, otorrhea persisted for longer than 20 years, suggesting that long-lasting inflammation in the ear might be a cause of temporal bone carcinoma. As pointed out by Varyberg [7], otalgia described as a dull and deep-seated pain might be a second key to suspect carcinoma. As otorrhea and otalgia are common complaints in otitis media, most such patients do not consider ear carcinoma, resulting in a delay in diagnosis. Further, a mass in the external ear canal might be misdiagnosed as an aural polyp or inflammatory granulation, indicating the necessity of histological study before a diagnosis of temporal bone carcinoma can be confirmed. The current treatment strategy for temporal bone carcinoma remains controversial, mainly due to the rarity of the disease. Complete surgical resection with a clear margin is ideal, but often difficult or impossible, particularly in patients with aggressive invasion to the surrounding structures. Prognosis in such cases is very poor. In our cases, invasion to the dura mater was noted in 14 patients and to the sigmoid sinus in 4 . All but two of these patients finally died of cancer metastasis to the brain or lung. Although the main lesion was removed by subtotal TBR, complete elimination of cancer cells invading into the dura mater or brain vessels appears impractical, even with the addition of postoperative chemoradiotherapy. We did not employ total TBR, as the procedure has greater morbidity without superior survival rates [7]. Recently, Sugimoto et al. [8] reported a histological study showing that epithelial-mesenchymal transition was highly expressed in cancer tissue with poor prognosis, and concluded that vimentin, a marker of epithelialmesenchymal transition, can be used to predict the prognosis of temporal bone carcinoma. Radiation is an important tool in the treatment of temporal bone carcinoma. Several authors have recommended radiation therapy for the treatment of middle ear carcinoma, showing that overall 5-year survival rate was as high as $41 \%[9,10]$. Gurgel et al. [11] reported a poor prognosis with radiation treatment alone, with 5-year survival rates in 215 patients of $74.4 \%$ by surgery, $9.1 \%$ by radiation, and $20.1 \%$ by surgery plus radiation, and accordingly disagreed with this recommendation. As pointed out by Gacek et al. [12] and Spector [13], once the tumor invades the middle ear, radiation therapy alone was curative in less than $23 \%$ of cases. Pfreundner et al. [14] noted that tumors extending beyond the surgical margins require radiation doses in excess of $66 \mathrm{~Gy}$, since tumors recurred in regions receiving less than $66 \mathrm{~Gy}$. Tumor cells at the surgical margins were hypoxic and therefore had decreased sensitivity to radiation. In our hospital, direct beam radiation of 66 Gy was routinely applied to lesions by packing the surgical defect with dimethyliso-propylazulene-ointment gauze to facilitate the tumor's sensitivity to radiation. Chemotherapy is also an important tool in the treatment of the head and neck carcinoma. At present, however, the effects of chemotherapy on this carcinoma have yet to be established [15]. Nakagawa et al. [15] administered anticancer agents (5-fluorouracil or TS- ${ }^{\circledR}$ ) postoperatively to enhance radiation therapy, and reported a 5-year survival rate for T3 and T4 lesions of $80 \%$ and $35 \%$, respectively. Recently, Ueda [16] reported the clinical effects of super-selective intra-arterial infusion chemotherapy were combined with radiotherapy for the treatment of external ear carcinoma. They tentatively applied this procedure to four patients and obtained complete remission in all cases with minor toxic effects. At present, however, the effects of this combined procedure in patients with advanced stage disease remain unclear. In our three patients considered unsuitable for surgery owing to invasion to the internal carotid artery or jugular vein, chemotherapy using TS-1 was combined with radiotherapy; two patients subsequently died of carcinoma while one patient with stage 4 SCC remains alive in a cancer-free condition. Tumor stage is an important factor in predicting the prognosis of temporal bone carcinoma. Yin et al. [6] re- ported that overall 5-year survival rate was 100\% in early-stage disease; while it was $67.2 \%$ for stage III and $29.5 \%$ for stage IV. In their review of the literature, Varyberg and Sataloff [7] reported that survival rates in combination treatment with surgery and radiation ranged from $75 \%$ to $100 \%$ for $\mathrm{T} 1$ and T2 lesions, $35 \%$ to $50 \%$ for T3 lesions, and $12.5 \%$ to $35 \%$ for T4 lesions. Histopathology of the tumor is also associated with prognosis. According to Gurgel et al. [11], 5-year survival rates of middle ear carcinoma were $23.9 \%$ for SCC, $65.0 \%$ for AC, $60.0 \%$ for other carcinoma, and $38.6 \%$ for non-carcinoma. In the present study, a statistical difference could not be observed among the three groups owing to the limited number of patients. Other factors reported to be associated with decreased survival rates were facial paralysis, positive surgical margins, advanced age, moderate-to-severe pain, dural involvement and lymph node metastasis, etc. For example, treatment failure rates were 
$34 \%$ in patients with mild facial paralysis, 50\% with moderate paralysis, and $62 \%$ with complete paralysis $[17,18]$. In our cases, facial paralysis was noted in nine patients, seven of whom died of carcinoma. As pointed out by Varyberg and Sataloff [7], treatment failure was mostly due to local recurrence. To improve the survival rate, initial surgery should be aggressive, as it offers the greatest chance for cure [19], and survival is reported to be better with more extensive surgery [20]. This is technically difficult, as the temporal bone locates closely to vital structures such as the brain, brainstem, cranial nerves and major vessels. In conclusion, external and middle ear carcinoma is curable when detected at an early stage. In cases extending deep into the middle ear or occurring in the middle ear cavity, prognosis is poor even with combination treatment with surgery plus chemoradiotherapy. Improving the survival rate in temporal bone carcinoma requires that treatment is started at an early stage.

\section{REFERENCES}

[1] S. E. Kinney and B. G. Wood, "Malignancies of the External Ear Canal and Temporal Bone: Surgical Techniques and Results,” Laryngoscope, Vol. 97, No. 2, 1987, pp. 158-164. http://dx.doi.org/10.1288/00005537-198702000-00006

[2] W. I. Kuhel, C. R. Hume and S. H. Selesnick, "Cancer of the External Auditory Canal and Temporal Bone," Otolaryngologic Clinics of North America, Vol. 29, No. 5, 1996, pp. 827-852.

[3] P. M. Stell and M. S. McCormick, "Carcinoma of the External Auditory Meatus and Middle Ear. Prognostic Factors and a Suggested Staging System,” The Journal of Laryngology \& Otology, Vol. 99, No. 9, 1985, pp. 847850. http://dx.doi.org/10.1017/S0022215100097796

[4] S. A. Moody, B. E. Hirsch and E. N. Meyers, "Squamous Cell Carcinoma of the External Auditory Canal: An Evaluation of a Staging System," American Journal of Otolaryngology, Vol. 21, No. 4, 2000, pp. 582-588.

[5] C. H. Chang, M. T. Shu, J. C. Lee, Y. S. Leu, Y. C. Chen and K. S. Lee, "Treatments and Outcomes of Malignant Tumors of External Auditory Canal,” American Journal of Otolaryngology, Vol. 30, No. 1, 2009, pp. 44-48. http://dx.doi.org/10.1016/j.amjoto.2008.02.007

[6] M. Yin, K. Ishikawa, K. Honda, T. Arakawa, Y. Harabuchi, T. Nagabashi, et al., "Analysis of 95 Cases of Squamous Cell Carcinoma of the External and Middle Ear,” Auris Nasus Larynx, Vol. 33, No. 3, 2006, pp. 251-257. http://dx.doi.org/10.1016/j.anl.2005.11.012

[7] M. Varyberg and R. T. Sataloff, "Hearing Loss. Chapter 21. Squamous Cell Carcinoma of Temporal Bone,” R. T. Sataloff and J. Sataloff, Eds., Taylor \& Francis, New York/London, 2005, pp. 545-571.

[8] H. Sugimoto, M. Ito, M. Hatano, S. Kondo, S. Suzuki and T. Yoshizaki, "Roles of Epithelial-Mesenchymal Transi- tion in Squamous Cell Carcinoma of the Temporal Bone," Otology \& Neurotology, Vol. 32, No. 3, 2011, pp. 483487. http://dx.doi.org/10.1097/MAO.0b013e31820d9654

[9] L. S. Pemberton, R. Swindell and A. J. Sykes, "Primary Radical Radiotherapy for Squamous Cell Carcinoma of the Middle Ear and External Auditory Canal: An Historical Series,” Journal of Clinical Oncology, Vol. 18, No. 5, 2006, pp. 390-394. http://dx.doi.org/10.1016/j.clon.2006.03.001

[10] A. R. Birzgalis, A. O. Keith and W. T. Farrington, "Radiotherapy in the Treatment of Middle Ear and Mastoid Carcinoma," Clinical Otolaryngology and Allied Sciences, Vol. 17, No. 2, 1992, pp. 113-116. http://dx.doi.org/10.1111/j.1365-2273.1992.tb01055.x

[11] R. K. Gurgel, L. H. Karnell and M. R. Hansen, "Middle Ear Cancer: A Population-Based Study,” Laryngoscope, Vol. 119, No. 10, 2009, pp. 1913-1917. http://dx.doi.org/10.1002/lary.20202

[12] R. R. Gacek and M. Goodman, "Management of Malignancy of the Temporal Bone,” Laryngoscope, Vol. 87, No. 10, 1977, pp. 1622-1634. http://dx.doi.org/10.1288/00005537-197710000-00003

[13] J. G. Spector, "Management of Temporal Bone Carcinomas: A Therapeutic Analysis of Two Groups of Patients and Long-Term Followup,” Otolaryngology-Head and Neck Surgery, Vol. 104, No. 1, 1991, pp. 58-66.

[14] L. Pfreundner, K. Schwager, J. Willner, K. Baier, K. Bratengeier, F. X. Brunner, et al., "Carcinoma of the External Auditory Canal and Middle Ear," International Journal of Radiation Oncology*Biology*Physics, Vol. 44, No. 4, 1999, pp. 777-788.

[15] T. Nakagawa, Y. Kumamoto, Y. Natori, H. Shiratsuchi, S. Toh, Y. Kakazu, S. Shibata, T. Nakashima and S. Komune, "Squamous Cell Carcinoma of the External Auditory Canal and Middle Ear: An Operation Combined with Preoperative Chemoradiotherapy and a Free Surgical Margin,” Otology Neurotology, Vol. 27, No. 2, 2006, pp. 242-249.

http://dx.doi.org/10.1097/01.mao.0000190463.88873.3d

[16] Y. Ueda, T. Kurita, Y. Matsuda, S. Ito and T. Nakashima, "Superselective, Intra-Arterial, Rapid Infusion Chemotherapy for External Auditory Canal Cartinoma," The Journal of Laryngology \& Otology, Vol. 123, No. S31, 2009, pp. 75-80. http://dx.doi.org/10.1017/S0022215109005143

[17] J. E. Medina, A. O. Park, G. L. Neely, et al., "Lateral Temporal Bone Resection,” American Journal of Surgery, Vol. 160, No. 4, 1990, pp. 427-433. http://dx.doi.org/10.1016/S0002-9610(05)80559-8

[18] R. T. Sataloff, D. L. Myers, L. D. Lowry and J. R. Spiegel, "Total Temporal Resection for Squamous Cell Carcinoma,” Otolaryngology-Head and Neck Surgery, Vol. 96, No. 1, 1987, pp. 4-14.

[19] M. Ito, M. Hatano and T. Yoshizaki, "Prognostic Factors for Squamous Cell Carcinoma of the Temporal Bone: Extensive Bone Involvement or Extensive Soft Tissue Involvement?” ActaOto-Laryngologica, Vol. 129, No. 11, 2009, pp. 131-139. 
http://dx.doi.org/10.3109/00016480802642096

[20] S. Prasad and I. P. Janecka, "Efficacy of Surgical Treatments for Squamous Cell Carcinoma of the Temporal
Bone: A Literature Review," Otolaryngology-Head and Neck Surgery, Vol. 110, No. 3, 1994, pp. 270-280. http://dx.doi.org/10.1016/S0194-5998(94)70769-3 